\title{
Organization and quality improvement of health care facility
}

Volume 5 Issue 5 - 2016

\section{Introduction}

Organization means organizing various activities to make workable units work them through authority. Each organization has distinct structure, different objective and functions. So each organization varies from one another. Organizational Leadership is not just as we think that there is a boss who commands dos and don'ts to the employees. But it is ability of management to understand the goals for the better progression of the organization and it is not just an art or science, but it is mixture of both. Unless the organization is good, there will not be good leadership to bring expounding result out of it. We have lot of organizational leadership like hospital leadership, situational leadership and classic leadership etc.

As far as the hospital organization is concerned it is not mere a transaction between employer and employees, instead it is very peculiar and very matrix and interrelated coordination of all other departments and understanding among them. The hospital is not like other organization, because for other organization we think of quality product, but for hospital organization we think of both product and the result of product which means in hospital the patient should get good equipment for the treatment and should get treated well. Or else the organization will not move smoothly, so there should be good planning, effective leadership and good understanding and helping attitude and good working environment. Now we would discuss on hospital as organizational leadership in brief. Hospital means health care center which can be a smaller one or bigger one. Usually at hospital the director is the main leader, who directs to promote the organizational growth and there will be an administrator who administers to maintain and manage the growth and progression of the hospital which is directed by director. Other leaders like assistant director, chief medical officer, doctors, hospital manager, human resource administrator, medical super indent, nursing super indent and all other sub ordinates. Even though all these leaderships are available in a hospital, still it will not make complete organization and to have complete organization, there must have departmental arrangement.

\section{Description}

Usually director is the superior one and all others come under him. Director must know how to manage failure and NOT how to give a lecture when success comes. Each hospital has rules and regulations which should be followed by all the staffs. before implementing a rule, the leaders and all other sub ordinates should discuss on how it will affect on organization and if found that So and So rule will not affect the organization (in the sense of progression and growth), then there is no use out of it, such rule should be avoided. If the rule is implemented, then it should be followed and result must be notified and convinced to others so that it is understood that the rule was useful for our organization and it was not waist. Leadership style of hospital is different for different organization. even though for hospital organization the director retains the power and decision
Nizamuddeen Kuniyil Abdul Kadar

Department of Anesthesia, Anesthesia Technician, Qatar

Correspondence: Nizamuddeen Kuniyil Abdul Kadar, Department of Anesthesia, Anesthesia Technician, Qatar, Email nizamuddeenkak@gmail.com

Received: August 25, 2016 | Published: September 12, 2016

making authority as much as possible, when the decision related to patient comes, it should be taken by doctors only and not by the director or administrator or any other leaders. This is the one of the main difference between hospital organization and other organization and other matters like admission, discharge and surgery all these come under doctors and not under the authority of director.

The well experienced employees are needed for hospital organization, as untrained staff does not know which tasks to perform or which procedures to follow. The decision of the director or administrator on staffs like doctors will affect the hospital management. So the director cannot make decision on doctors for patient health related issues, because they are the main workers of the hospital. Without doctors it impossible to lead the hospital with success. There must be enough paramedical staff and nursing staff to assist the doctors. It is very important that hospital department should be constructed and arranged in facilitated area. we cannot keep operation theater, post-operative unit and intensive care unit far away similarly the department like biochemistry, pathology, microbiology and other testing department must be altogether so that all the test can be done at the same place otherwise patient will have to run from one place to another. So arrangement of blocks and units must be very facilitated and easier to find because the people are not healthy people, but they are sick. The hospital should have modern equipment for better treatment. Other leader should advise for better progress, correct their mistakes, and appreciate them when they do good things instead of shouting always at them.

Always the leader should be in pleasant mood not only to the staffs but also to the patients. Leaders should keep the staff informed about everything that affects their work and share decision making and problem solving responsibilities. The organization mainly aims for solving problems, maximizing efficiency and productivity.

Solving problem is the very important thing and very sophisticated matter for an organization. The organization may come across problems, so to solve it the root cause for the problem should be known. The problem can be lack of staff enough staffs for the organization. So adequate staff should be brought, It is the duty of hr department, so the 
HR department should be equipped with. Looking only at maximizing efficiency is not the good aim, but besides this the facilitates and benefits to the employee must be provided. Productivity is the goal of every organization including hospital. For better productivity, the better treatment, good facilities should be provided for the patients and staffs.

If the organization aims good productivity, and still they do not offer good facilities and good treatment for the patients, the chance of good productivity is less. If the organization gives what the patient really wants and how the patient really treated, then the organization of course will be in good progression. To implement this theory requires depth information about the situations. Maximizing efficiency in a hospital is done by providing well qualified doctors and well experienced paramedical staff and nursing staffs. If the society likes the organization, this is the turning point of organization towards the high productivity. Neatness is one of the main factors which show the characters of the organization. If the hospital is very neat and clean, it makes the patients to be satisfied. However, at last whatever we do is not for others but it is for us only.... all the leaders would like to make the organization silent, so this is only achieved by understanding between all the involvers of the organization, he can be a leader, staff, patient or patient relative. All these together bring the silent working environment. Leader of organization should be honest and trustworthy. The leader should appreciate when the staff does good things so that it will make him happy and he will work honestly for the organization, which leads to growth of hospital. And this also improves communicative relation between the leader and employee of the organization, the leader should not do whatever he wants for his organization. Misuse of ownership of the leader on the employee results in deterioration of employees' working environment. The staff should be given respect and power in an organization, though the leader has more power in the organization and good communication between various branches of an organization improves the quality, and thereby productivity and reputation to the organization. There are many organizational leaderships viz.

\section{Autocratic leadership}

It is an extreme form of transactional leadership, here the leader shows extreme power on his employees or subordinates. Subordinates do not get much opportunities to make suggestion. Even if they get little opportunity, it may not be taken into accountability. This type of leadership usually applies for small organization. It has lot of disadvantages like leader will not trust employee, leader gives punishment for mistakes and do not allow employee to suggest his opinions.

\section{Transactional leadership}

It is a type of leadership style, here the leader promotes efforts of his employees via both rewards (good payment) and punishment. In this type of leadership the leader tries to find faults and deviation of the employees. Leader punishes and takes decisions in order to get high productivity without any discussion between employee. He may give opportunity for employee, but still at last he will decide what to be done. One of the advantage of transactional leadership is it gives good productivity with less time.

\section{Bureaucratic leadership}

Bureaucratic leaders do as per the rule mentioned in the book, and he watches whether his employees follow the rule written in the book. This is good in the case of serious work, related to toxic matter. This type of leadership does not show us both practical and theoretical, but it shows only theoretical matter.

\section{Charismatic leadership}

This is somewhat similar to the transformational leadership, here the leader tries to motivate the employee by communicating with them. But here leader mainly concentrates on employee and not on the team. Displaying charismatic leadership is one of the most effective ways to boost everything from motivation and creativity to productivity and plain satisfaction. Leader may be charismatic in both charismatic leadership and transformational leadership.

\section{Transformational leadership}

Transformational leadership was first mentioned in 1973 by Downton.j and V. Rebeli in the sociological study. This leadership style makes the organization very effective with a lot of communication between the employees and leaders, and listen to the opinion and suggestion of employee. In this type, leader will not take only his decision into the accountability, but he will also give opportunity for subordinates, so here the employee also acts as small leader.

This leadership style teaches all the staffs how to lead the organization and it makes everybody to be responsible one. Leader raises connections and that raises the level of motivation and morality between employee and leader.

This transformational leadership implies what I do is for us, whereas the transactional leadership implies if you help me then I will help you. It means if the leader rewards more, then I will work more, but in transformational leadership, all the employees take responsibilities and are allowed to express their opinions.

The selected style for the hospital is transformational leadership. If other style is chosen, then the hospital organization cannot be managed effectively, because as per the other organizational leadership, the leader who will decide what to be done and leader will take power on employee and employee will not be allowed to share his opinions. The hospital needs effective works from the employee. Responsible manager and the employee should be able to take decision if necessary. Hospital is complex and critical organization, where taking decision only by leader may not be agreeable and cannot be acceptable. Sometimes doctors will have to take decisions if the leader takes the decision instead of doctor, the organization structure will not be proper. For instance, if the patient is required to be sent to major hospital for major surgery, then this decision of discharge and related matter should be decided by health care staff and not by the leader. Because doctor has more experience in this field than leader. So here leader should permit the employee to take the decision and implement it whenever needed. This kind of style is achieved only by transformational leadership and not by any other style or behavior. transformational leadership raises moral values and sharing opinions and productivity. Though leader has power in this leadership, still he gives the power to his employee to use in his department. The organization should look not only at the patients, but it should provide rewards to the employee too. transactional leadership provides only the effective treatment to the patient but does not give morale value to the employee. So this is one of the reason why I did not choose transactional leadership, and another reason is in transactional leadership the leader can punish and suspend, and even dismiss the employee without any major reason and employees stay in this organization, only for rewards, if the reward is good, then employee is ready to continue his work and If the reward is less, the employee will leave at any time. If the employee gets responsibility and respect besides reward. Then employee can not resign from the organization without prior notice. So the leader will be able to substitute a new employee. So this style is suitable for all organization especially hospital. In transformational 
leadership the leader gets what really wants from the employee for the hospital organization. Transformational leadership gives the staff freedom as well as responsibility. The employee can produce good result only if the employee should be free of stress from both the leader and organization, so to achieve this the best style or behavior is transformational leadership. Transformational leaders will be ideal for other member of the organization, they inspire and motivate the employees, provide intellectual stimulation and transformational leader pay attention to the employees' needs.

Hospital patient's satisfaction is characterized by the how many patients are satisfied with the treatment provided by hospital. All the hospitals organization maximum tries to provide good treatment to satisfy the patient so that the organization gets more patients. Whatever management we do in the hospital organization is to provide satisfaction to the patients. If the patient is satisfied then the all the leaders, employees are benefited. That is why I chose the patient satisfaction is the main theory for hospital organization. If we look at aims of any organization whether it is hospital or any other company whatever it may be. All of the organization leaders mainly aims or goals to make the customer to be satisfied. Because the customer satisfaction is the primary factor for the progression of an organization.

The measurement of patient satisfaction has increased due to three changes in health care. First the role of clinicians has changed from helping patients through their illness to where the doctor expected to cure or alleviate the symptoms. Secondly patient has got rights to take decision. Third, patients are well informed before what is going to do on him. The major satisfactory theories are established in 1980s. When we think of patient satisfaction, the main factors which give the satisfaction are well qualified doctors, modern equipments experienced nurses, neatness of clinics. Organization leaders should seek what makes the patient satisfied then implement those things so that organization can increase productivity besides all these facilities, if the patient is treated well with less fee, then the patient will be satisfied very well.

So the organization leaders should hardly try to provide better treatment with less fee. Patient should have trust on doctors, then half of the illness get cured. Organization should have famous doctors and nurses should be kind to the patients to make the patient happy. Hospital organization makes sure that the patient is not given any treatment unnecessarily. Good communication between nurses and patients give more satisfaction to the patient than any other thing. Hospital organization should able to provide tasty and nutritional food for better health of the patient.

Leader should not act like boss though he is the leader of the hospital and leader should not interrupt the patient and staff. Though the maximizing productivity is the goal of hospital organization, the leader should not target only on the productivity, because if the leader goals only on the productivity, the customer will get negative thinking on the organization so he will feel bad on such organization, so he will come next time. Though hospital has goal on productivity, it should indirect aim. Not direct, the direct aim is patient satisfaction. Once the hospital organization full fills the patient satisfaction then indirectly the productivity also increases.

Transformational leadership style is best, because transformational leadership style produce good output, approaches to leadership, creating distinct advantages for the organization. A leader will have integrity and will be able to communicate about his goals to employee and he can expect best from his employees. He inspires to look beyond their own interest. Leader gives stimulating work and takes the time to organize good task and employee. Transformational leadership has unique advantages like it uplifts the strength of the team. Communication is the main factor which makes the organization very prograssive in transformation leadership, if any failure occurs in the organization, we cannot blame one person who is responsible for this, but all are responsible for that. All the employees and leaders should able to overcome failure and make to success. The transformational leadership style teaches us not to blame the employee and to manage and overcome the failure. All employees and leaders can become friendly to each other and correct the faults each other. Transformational leadership style makes the situation where all can participate in meeting.

\section{Conclusion}

Primarily, I will recommend to approach transformational approach and to become best approach or style. I would like to add one more style in addition to transformational leadership style. Why I recommend so is that every leadership style will have advantages and disadvantages. So first what I did is I chose Transformational leadership which has maximum advantages. The leadership style which I chose will have little bit disadvantage also. So what I would like do is that take such disadvantages and substitute with advantages of other leadership style, So it makes our leadership to be best one. For instance, the transactional leadership can be applied for urgent work very effectively, because the leaders urge to do the work faster, and transformational leadership takes time to complete task and get good result also. So the good points of the transactional leadership should be selected and implemented in our organization, so that we can be the best organization. Transactional leadership can bring out good result with less time. So if we have organized in such a way so that we can practically apply for the success of the hospital. Both type of leadership makes the organization unique in case of morale value and satisfaction of the followers, within less time. This timing main factor which makes the the uniqueness. hardworking and commitment to the organization, good reward to the employee and consuming more time can make any organization to be successful, making the employee hardworking, commitment, truth full person with less time is unique power of the organizational leader who organizes very effectively. I recommend the time management should be carefully watched by the leader. Because timing is the beauty of the organization. It shows how much the leader and the employee are sensitive. The leader should not be careless. I conclude here with one more recommendation that the leader besides being leader of the follower a, he should be an ideal follower too so that the newly joined employee or manager can learn and try to become an ideal follower of the organization.

\section{Acknowledgments}

None.

\section{Conflicts of interest}

The authors declare there is no conflict of interests.

\section{Funding}

None. 